\title{
Flight Dynamics Modeling and Simulation of a Damaged Transport Aircraft
}

\author{
Gautam H. Shah ${ }^{1}$ \\ NASA Langley Research Center, Hampton VA 23681 \\ and \\ Melissa A. Hill ${ }^{2}$ \\ Unisys Corporation, Hampton VA 23666
}

\begin{abstract}
A study was undertaken at NASA Langley Research Center to establish, demonstrate, and apply methodology for modeling and implementing the aerodynamic effects of MANPADS damage to a transport aircraft into real-time flight simulation, and to demonstrate a preliminary capability of using such a simulation to conduct an assessment of aircraft survivability. Key findings from this study include: superpositioning of incremental aerodynamic characteristics to the baseline simulation aerodynamic model proved to be a simple and effective way of modeling damage effects; the primary effect of wing damage rolling moment asymmetry - may limit minimum airspeed for adequate controllability, but this can be mitigated by the use of sideslip; combined effects of aerodynamics, control degradation, and thrust loss can result in significantly degraded controllability for a safe landing; and high landing speeds may be required to maintain adequate control if large excursions from the nominal approach path are allowed, but high-gain pilot control during landing can mitigate this risk.
\end{abstract}

\section{Nomenclature}

$\begin{array}{lll}\mathrm{CDA} & = & \text { Commercial Derivative Aircraft } \\ \mathrm{CRAF} & = & \text { Civil Reserve Aircraft Fleet } \\ \mathrm{FAA} & = & \text { Federal Aviation Administration } \\ \mathrm{ft} & = & \text { foot } \\ \mathrm{GTM} & = & \text { Generic Transport Model } \\ \mathrm{lb} & = & \text { pounds } \\ \mathrm{MANPADS} & = & \text { Man-Portable Air Defense System } \\ \mathrm{NASA} & = & \text { National Aeronautics and Space Administration } \\ \alpha & = & \text { Angle of attack } \\ \beta & = & \text { Angle of sideslip }\end{array}$

\section{Introduction}

The threat posed by Man-Portable Air Defense Systems (MANPADS) to transport aircraft is one of growing concern worldwide. As evidenced by attacks on an Arkia Airlines aircraft in Mombasa, Kenya in 2002 and a DHL cargo aircraft in Baghdad, Iraq in 2003 (Figure 1), the threat is not limited to military operations, but is of concern to civil aviation as well. With the military's use of the Civil Reserve Aircraft Fleet (CRAF) to ferry troops, as well as increasing use of commercial derivative aircraft (CDA) for military applications, there is a relevant need

\footnotetext{
${ }^{1}$ Assistant Head, Flight Dynamics Branch, MS308, Senior Member AIAA
}

${ }^{2}$ Simulation Software Engineer, Unisys Corporation 
to evaluate the survivability of such transport aircraft in the aftermath of a potential MANPADS encounter from the time of impact to the completion of a safe landing.

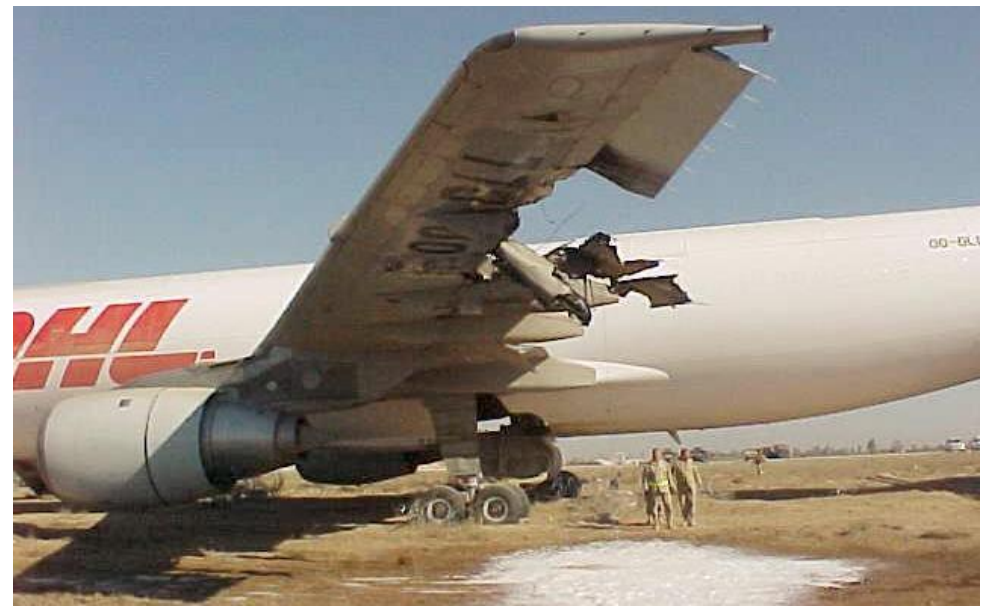

Figure 1. MANPADS damage to a DHL cargo aircraft

Analyses conducted to assess vulnerability and ultimately overall survivability of aircraft subject to MANPADS damage have generally been focused on physical effects, e.g., damage to the structure, vital components, and major systems such as hydraulics or fuel. For smaller tactical vehicles such as fighter/attack aircraft, the resultant damage may often be catastrophic, or cause such severe stability or controllability problems so as to render the aircraft immediately unrecoverable. For larger transport aircraft, however, due to their sheer size and distributed systems, as well as their inherent stability, there is a greater chance that the aerodynamic or structural integrity as well as controllability, while potentially being severely compromised, may not be catastrophic and adequate control may be available to allow a safe landing. Assessing the continued-flight capability, from an aerodynamic and controllability standpoint, of a transport aircraft to safely land with damage is of considerable interest and value because crew and passengers are generally unable to escape a transport aircraft in flight.

\section{Technical Objectives and Approach}

The objective of this activity was to establish, demonstrate, and apply methodology for modeling and implementing the aerodynamic effects of MANPADS damage into real-time flight simulation, and to demonstrate a preliminary capability of conducting an assessment of continued-flight (and thus survivability) through piloted flight simulation. The approach to achieve these objectives was in four parts: Determination of appropriate damage conditions representative of a potential MANPADS encounter with a transport aircraft; Modeling and implementation of the aerodynamic effects of such damage into flight simulation; and Development of an appropriate flight simulation model; and Conducting flight simulation to assess its utility for evaluating survivability. A discussion of each of these four activities is presented below.

\section{A. Determination of damage conditions for modeling}

Because of the infinite number of potentially significant hit-point locations on a transport aircraft, as well as their disparate effects, the study focused on damage to one wing and, further, primarily considered damage that would be expected to have significant controllability effects. Four conditions were selected for modeling and simulation. The damage conditions, and the rationale for their selection, are as follows:

1. Loss of an outboard trailing-edge flap - This condition is intended to be representative of the damage resulting from the DHL A300 MANPADS encounter in 2003 in Baghdad, Iraq. Figure 1 shows that a sizable portion of the left wing's outboard flap had separated from the aircraft during the incident. Despite total loss of hydraulics and the aerodynamic asymmetry from the missing flap section, the crew was able, 
through very skillful airmanship, to maneuver the aircraft using thrust alone, and successfully return to the airport and land, although the aircraft was severely damaged during the landing and rollout.

2. Loss of the leading-edge slat - This condition is based upon the damage that occurred on an El A1747 cargo aircraft during departure from Amsterdam in 1992. An inboard engine separated from the wing, damaging the leading edge and also causing the separation of the outboard engine on the same wing. Contending with thrust and aerodynamic asymmetries, the crew successfully maneuve red the aircraft back towards the airport, but eventually lost control during the landing approach and crashed into an apartment building, resulting in over 50 fatalities. Although not a hostile incident, the resulting wing damage is considered potentially representative of what could occur if a MANPADS encounter caused pylon damage resulting in engine separation.

3. Loss of the outboard $1 / 4$ of the wing ( $25 \%$ semi-span) - This condition was selected not because of any actual event or example, but representative of damage resulting from a MANPADS impact to, and potential subsequent structural failure of, a wing spar. The $25 \%$ semi-span location was chosen because the aerodynamic effects, though significant, were not severe enough to render the aircraft uncontrollable.

4. Large hole in the outboard section of the wing - This condition, as with the previous one, was not based on any actual event, but was considered representative of potential damage from a hydrodynamic ram event stemming from high-energy shrapnel impacting a full fuel tank in the wing. The hole size was modeled as the largest possible hole that could be created on the outboard wing between nominal front and rear spar locations (under the assumption that a hole of larger size would be structurally catastrophic due to spar damage).

Thus the selected conditions are representative ones based on a combination of actual events and engineering judgment on possible damage that would have aerodynamic controllability implications on an impaired, but still flyable, aircraft. In all cases, the primary effect of the damage is an aerodynamic roll asymmetry requiring varying levels of lateral control for compensation.

\section{B. Modeling of damage effects}

\section{Aircraft configuration description}

The study was conducted for a generic medium-range twin-engine transport aircraft, with a wingspan of approximately 125 feet and maximum gross weight in the 200,000-lb range (Figure 2). This configuration, named Generic Transport Model (GTM), has been studied for over ten years within the NASA Aviation Safety Program, and was chosen for this activity to leverage its extensive wind-tunnel, modeling, and simulation database. 


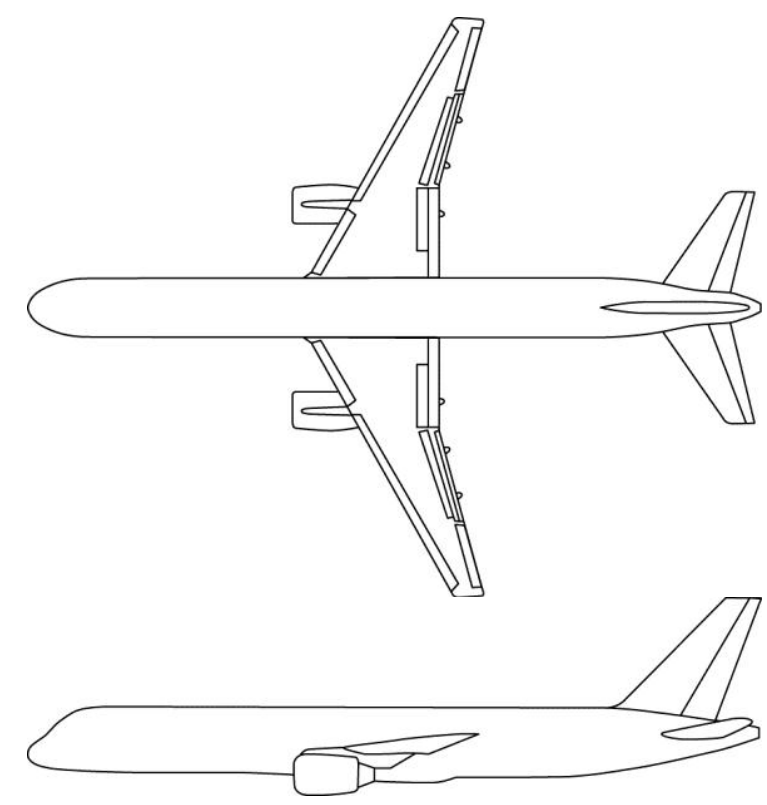

Figure 2. Generic transport aircraft configuration

\section{Aerodynamic effects}

The aerodynamic effects of the four damage conditions were modeled based upon data from wind tunnel tests of the GTM configuration. The tests were conducted on a 5.5\%-scale model of the GTM configuration in the NASA Langley 14 by 22 Foot Subsonic Tunnel. Conventional static tests were conducted at a dynamic pressure of $10 \mathrm{lb} / \mathrm{ft}^{2}$, corresponding to a Reynolds Number of $0.54 \times 10^{6}$ based on mean aerodynamic chord. Forced oscillation tests were also conducted in this facility. The model was oscillated in a sinusoidal fashion at frequencies and amplitudes that correspond to typical full-scale short-period and Dutch-roll motions. Oscillation tests were conducted individually in the pitch, roll, and yaw body axes to acquire aerodynamic damping characteristics. For all static and dynamic tests, six-component force and moment data were acquired using an internal strain-gauge balance.

The GTM configuration has been tested extensively under the NASA Aviation Safety Program to quantify aerodynamic and control characteristics over a broad angle of attack and sideslip range for loss-of-control and upset recovery modeling research, as well as general research on the effects of airframe damage. A substantial number of damage conditions have been studied, including those involving damage to the wing and horizontal and vertical tails. Detailed information on testing conditions and general aerodynamics of the basic and damaged GTM configuration along with discussions on general modeling issues, are available in published reports ${ }^{1-4}$.

Figure 3 shows the GTM model as installed in the 14 by 22 Foot Tunnel, and a sketch of the four damage conditions described earlier. The damage conditions were represented on the model by removal of the relevant section of wing; examples of conditions 1 and 3 are shown in the inset of figure 3. For condition 2 (slat damage), the rounded wing leading edge was removed, leaving a flat, vertical face as the wing leading edge. For condition 4 (wing hole), a constant-diameter hole extended from the upper to lower wing surface, allowing flow-through of the freestream air. As figure 3 indicates, all the damage conditions were modeled as smooth and/or straight break-lines. While actual damage conditions would certainly not be expected to have such clean separation lines, it was assumed that the effect of irregular breaks or "jagged edges" relative to smooth edges would be secondary to the main aerodynamic effect of the lost surface. Subsequent testing of irregular edges on selected damage cases confirmed that their effect was not significant in terms of aerodynamic stability or controllability. 


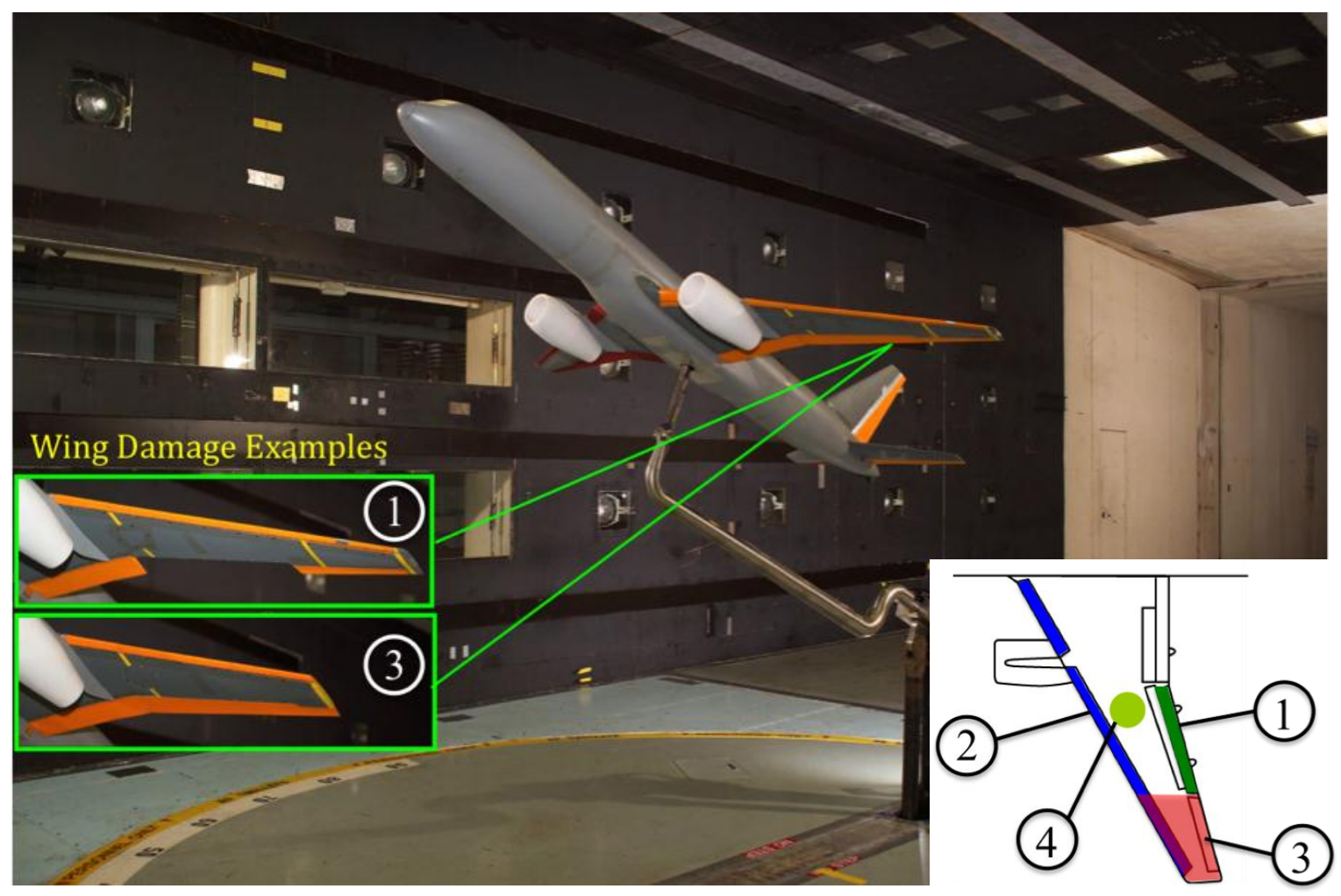

Figure 3. Damaged GTM configuration in the NASA Langley 14 by 22 -Foot Tunnel

Force and moment data were acquired for the undamaged and damaged cases over a large range of angleof-attack $\left(-10^{\circ} \leq \alpha \leq 90^{\circ}\right)$ and angle-of-sideslip $\left(-45^{\circ} \leq \beta \leq 45^{\circ}\right)$. The primary effect was roll asymmetry, which increases with angle of attack, as shown in figure 4. Plots of the variation with sideslip at two angles of attack follow (figures 5 and 6).

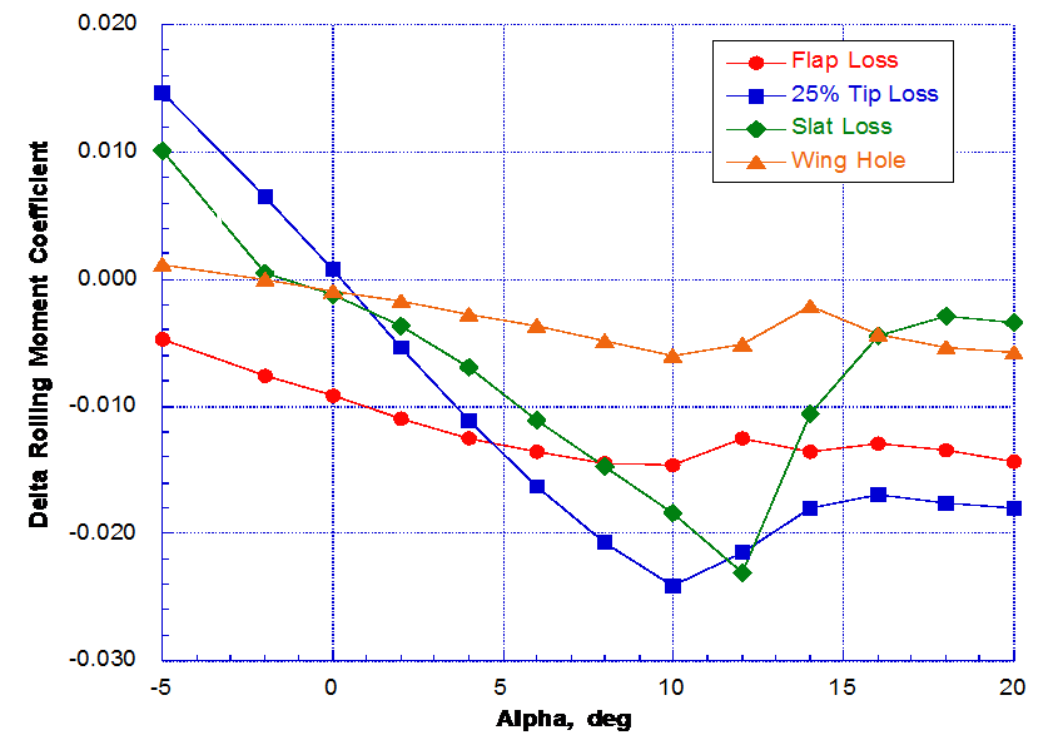

Figure 4. Incremental rolling moment coefficient versus angle of attack at zero sideslip 


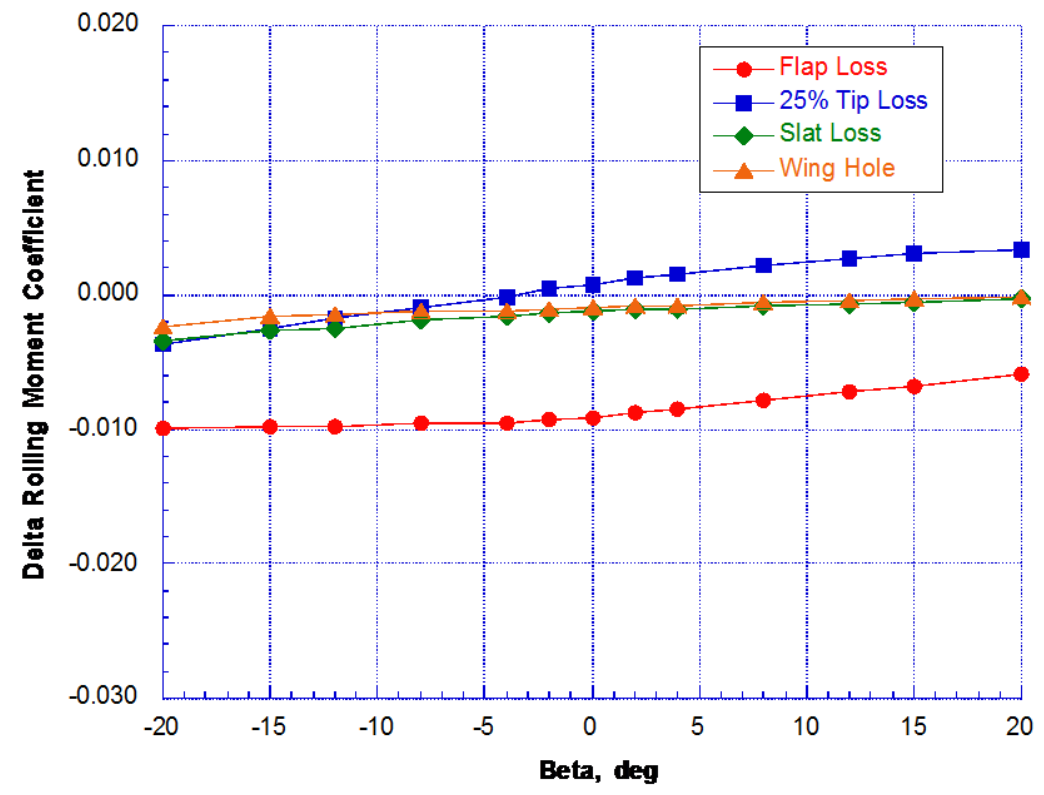

Figure 5. Incremental rolling moment coefficient versus angle of sideslip at $\mathrm{AOA}=0^{\circ}$

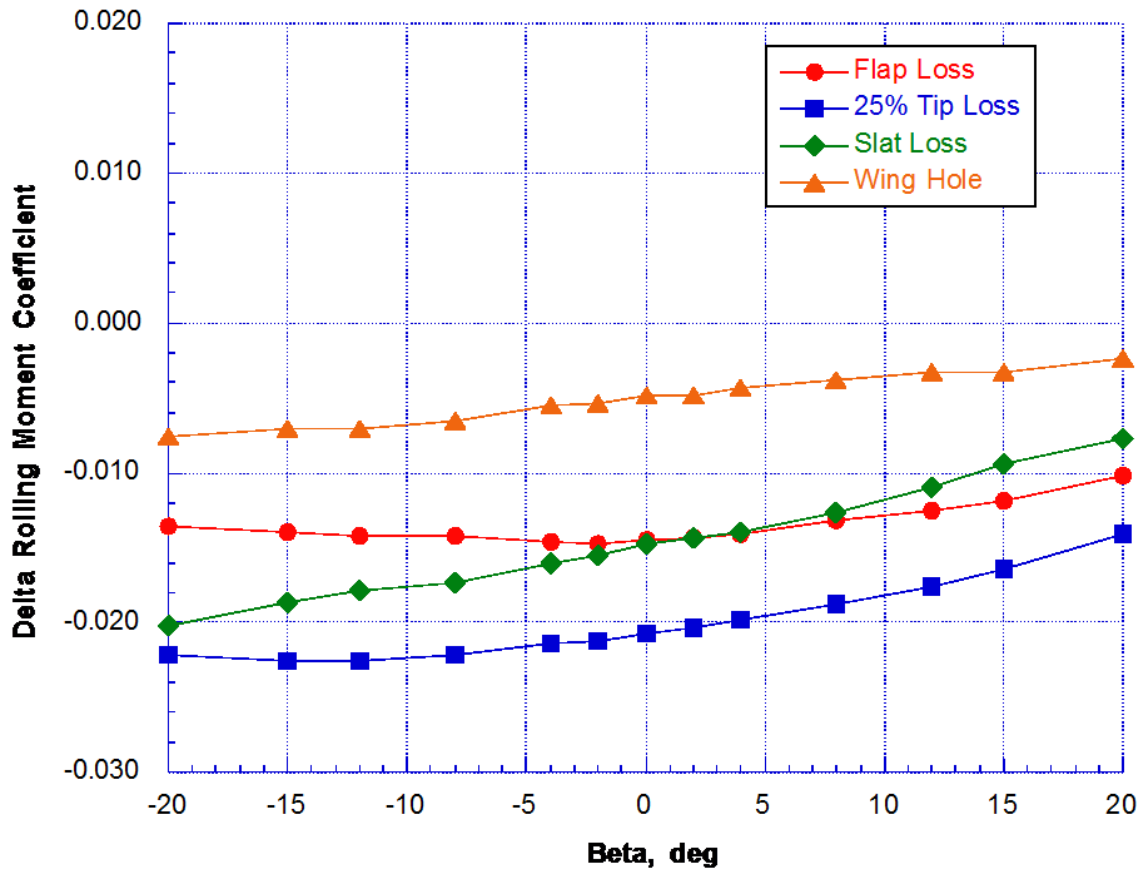

Figure 6. Incremental rolling moment coefficient versus angle of sideslip at $\mathrm{AOA}=8^{\circ}$ 
The data were linearly interpolated over the angle of attack and sideslip range using the Matlab function griddata at series of breakpoints from $-5^{\circ}$ to $40^{\circ}$ angle of attack, and $-20^{\circ}$ to $+20^{\circ}$ angle of sideslip. The incremental forces and moments relative to the undamaged case were then calculated for each component at each alpha/beta point. This resultant matrix of incremental force and moment coefficients formed the basis of the damaged aircraft aerodynamics model.

Damage affecting the static aerodynamics of the wing also affects the dynamic characteristics of the aircraft, primarily the rolling moment due to roll rate, or roll damping. A conventional transport configuration typically has strong stabilizing roll damping in the normal flight regime, which decreases as the aircraft approaches stall angle of attack $\left(12^{\circ}-14^{\circ}\right.$ angle of attack). Figure 7 shows the affect of damage on roll damping characteristics. Damping was seen to degrade between $10 \%$ and $25 \%$ from nominal for low angles of attack for flap, tip, and slat loss (the effect due to the outboard hole was minimal, less than $4 \%$ of baseline). The effect of damage on roll damping was applied to the aerodynamic simulation as a multiplying factor to the nominal roll damping proportional to the levels shown in figure 7.

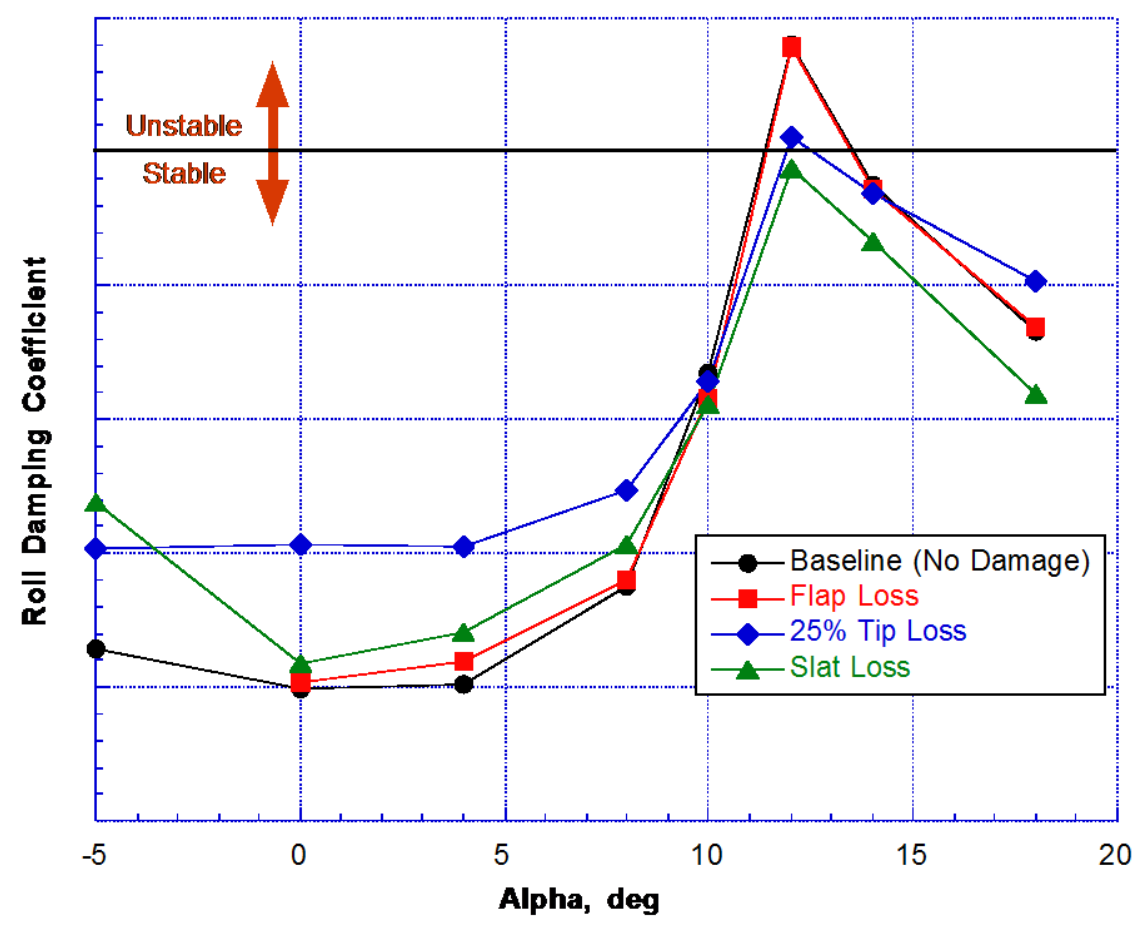

Figure 7. Roll damping coefficient versus angle of attack

\section{Mass properties effects}

Loss of wing structure of this nature will result in several changes to the overall mass properties of the aircraft, including changes in gross weight, center-of-gravity (laterally as well as longitudinally), and moments of inertia. It was unknown if such effects would be significant in terms of overall controllability, thus it was desired to make a basic attempt to evaluate its importance.

Because it is difficult to quantify the specific mass properties of the damaged or lost components, it was not practical to model the specific effects for the four damage conditions. Instead, the effect was modeled as the mass properties increment from the physical loss of a large wing-mounted transport-category turbofan engine (known quantities in the Generic Transport Model simulation). Because of the engine's weight and location, such an increment would be expected to have an effect greater than that of any of the four damage conditions, thus if the 
mass effect of the loss of an engine does not have a significant effect on overall controllability or stability, then the actual effect of mass property changes from the four damage conditions would be expected to be even less.

\section{Systems effects}

In addition to aerodynamic or structural implications, a MANPADS impact or detonation on or near the wing can be expected to damage components or systems internal to the structure, such as hydraulic or electrical systems. Such systems can also suffer degradation as a result of engine damage, as their power is generally derived from the propulsion system.

The loss of, or damage to such systems, particularly hydraulics, can have a substantial effect on the operation of the aircraft flight control systems. Although flight control surface actuators are generally redundant, and rely upon multiple independent hydraulic systems, the loss of one or more of those systems can result in lower actuation rates or diminished range of travel of various control surfaces. This can cause degradation in control or maneuvering capability for the aircraft through sluggish or delayed response to control inputs.

While a hydraulic-system degradation would be expected to have an impact on multiple control surfaces, for the purposes of this study the effects were focused on the primary issue - roll controllability with wing damage hence only the effects on the damaged-wing aileron were modeled. The effect was modeled as two discrete levels of degradation: a 50-percent reduction in the deflection rate of the aileron on the damaged wing; and a total failure of the aileron on the damaged wing (surface frozen at zero deflection). It should be noted that for condition 3 (25\% tip loss), it was not necessary to model the control degradation since the left aileron is totally removed from the wing.

\section{Flight Simulation Development}

\section{Description of flight simulator}

The flight simulation used for this study was a real-time piloted engineering simulator representative of a medium-range twin-engine commercial transport of the characteristics described earlier. This simulator is fixedbased, and is representative of a current transport flight deck. The facility incorporates high-resolution visual displays, fully functioning pilot controls with representative force-feel and a stick shaker system, a flight management system, and representative flight displays (Figure 8). The simulation fidelity is comparable to an FAA Level-D high-fidelity airline training simulator. The aerodynamics model is based upon flight-validation of a production transport aircraft configuration similar to the Generic Transport Model, and has been enhanced with results from wind tunnel tests of the GTM at large angles of attack and sideslip.

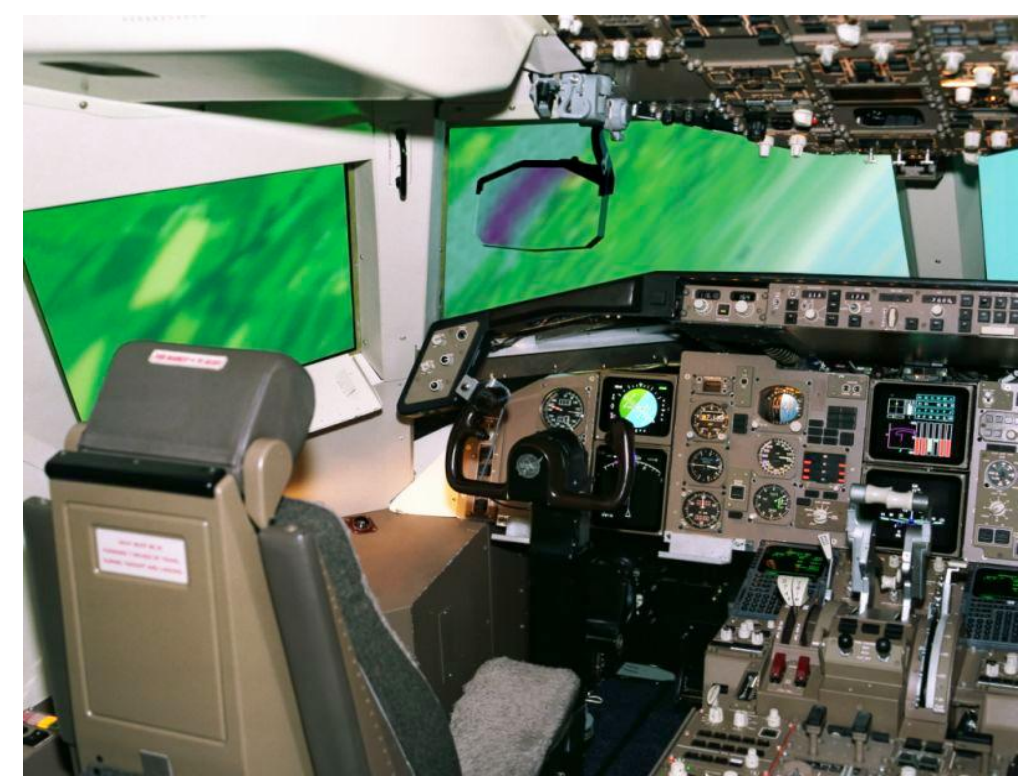

Figure 8. Photo of NASA Real-Time Simulator Flight Deck 


\section{Incorporation of damage effects}

The aerodynamic increments due to damage, were incorporated into the aerodynamics model of the GTM simulation as additions to the total aerodynamic forces and moments. The incremental aerodynamic coefficient for each of the three forces and three moments was computed based on angle of attack and sideslip, and linearly interpolated within the matrix as necessary. These 'damage increment' coefficients were then added to the total aerodynamic forces and moments computed at each iteration of the simulation loop. The roll damping multiplier was applied to the rolling moment increment due to roll rate as computed during each iteration of the simulation loop.

\section{Piloted Flight Simulation}

\section{Flight profiles}

Each of the damage conditions were flown at three flight conditions: low-altitude level flight; takeoff/climb-out; and approach/landing. Each flight was started with the undamaged configuration and the damage effect was instantaneously applied after a short period of normal flight with trimmed thrust and controls.

Different aspects of controllability or maneuverability were studied for each type of flight condition. For the level-flight case, after damage was applied, airspeed was decreased while maintaining constant altitude (thus increasing angle of attack) to observe the increasing roll control required to compensate for the aerodynamic roll asymmetry, and to define the limitations of that control. For the takeoff case, the ability to maintain level flight and complete maneuvers required to return towards the runway was studied. For the landing case, the aircraft was flown all the way to touchdown to observe the level of control needed as the aircraft decelerated during approach.

\section{Damage conditions/combinations flown}

The aerodynamic, mass properties, and systems effects were incorporated into the real-time full-scale piloted simulation, and were flown in various combinations:

- Aerodynamic changes alone

- Aerodynamic plus mass properties effects

- Aerodynamic plus mass properties effects, and control degradation

Mass property changes were not seen to have a substantial effect on flight characteristics relative to the aerodynamic and control effects; the discussion below is therefore limited to aerodynamic and control issues.

\section{Discussion of Results}

Because the primary effect of wing damage is a rolling moment asymmetry and some reduction in roll damping, the main flight dynamics effect is on roll controllability. Significant amounts of control wheel (roll) input are needed to compensate for the asymmetry, reducing the amount of roll control available for maneuvering the aircraft. The rolling moment asymmetry increases with angle of attack (Figure 4); therefore, increasing roll control (usually from ailerons and spoilers) would be required to maintain wings-level flight as the aircraft decelerates during approach to landing. Exacerbating this situation would be the possible systems damage that can degrade or eliminate the functioning of crucial control effectors, including ailerons or spoilers. Figure 9 shows the increase in roll control requirements as speed decreases (angle of attack increases) during a level-flight deceleration. 


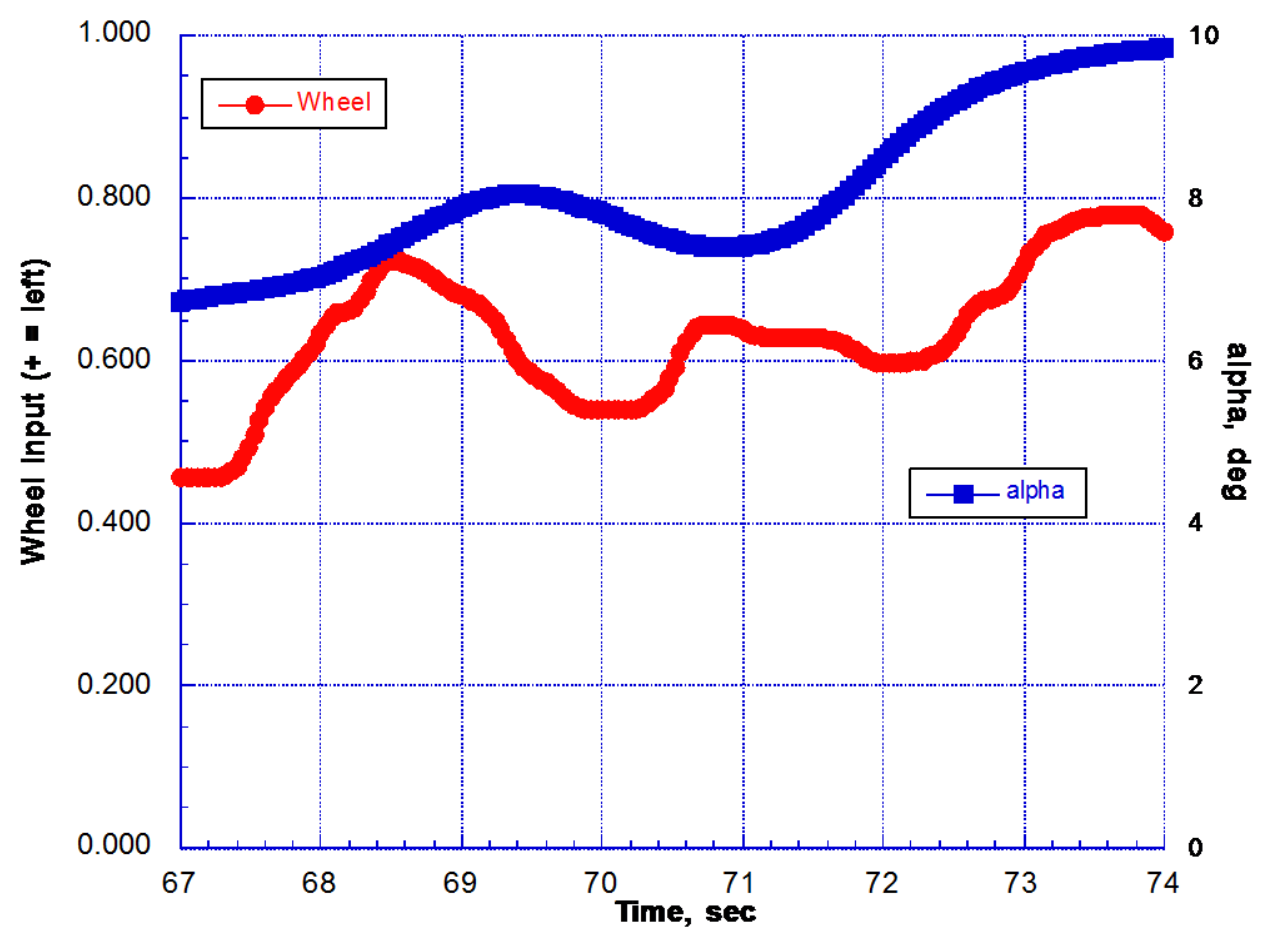

Figure 9. Wheel input variation with Angle of Attack, 25\% Tip Loss Condition

Minimum controllable speed, therefore, will be limited to a condition where roll control authority is available for asymmetry compensation, with enough excess to maneuver the aircraft as required for a safe landing. In situations where damage asymmetry is high, lateral control capability is limited, and high-lift systems are unavailable, the minimum control speed may be considerably higher than a nominal, or even safe, landing speed. Thus a situation may result where the aircraft damage is controllable in flight, but not necessarily at landing, except at high speed. In such situations, the ultimate survivability will be determined by a combination of the vehicle's controllability, crashworthiness, and occupant safety systems.

For damage resulting in small levels of roll asymmetry (e.g., outboard hole, and/or low angle-of-attack), if the required lateral compensation was within autopilot control authority, leaving the autopilot engaged was an effective measure in controlling the asymmetry, particularly during the landing approach. If, however, the required roll control was beyond autopilot authority, the engaged autopilot was a hindrance, as it would hold the control wheel at the limit of its authority, and require significant force input to override. It should be noted, however, that this effect was observed for the implementation of the autopilot for this specific research simulation, and the logic and force requirements for autopilot disconnect varies across aircraft models, and therefore the utility of keeping the autopilot engaged will be dependent upon the specific configuration of interest.

Conventional large transport aircraft possess a significant amount of lateral stability, or effective dihedral, which generates a compensating rolling moment in response to sideslip. Therefore, the use of rudder to create sideslip and thus generate a rolling moment was seen to be an effective means of compensating for the aerod ynamic roll asymmetry due to wing damage. The rolling moment thus generated was no longer required to be provided by the ailerons and spoilers, allowing a greater portion of their authority to be used for lateral control and maneuvering, instead of roll asymmetry compensation.

The use of rudder and sideslip in this way can be viewed in a related fashion to the use of rudder and aileron to counteract the effect of an engine-out situation, where rudder is used to generate a compensating yawing moment and counteract undesired sideslip, and ailerons would be used to bank into the "good" engine thereby 
kinematically reducing sideslip and reducing the amount of rudder required. In other words, during engine failure, aileron is used to reduce the amount of rudder required for control, while in the case of roll asymmetry due to damage, rudder is used to reduce the amount of aileron required for control.

For the basic airplane, roll damping diminishes as the aircraft approaches stall AOA. Wing damage was seen to further degrade roll damping. If lateral control authority is diminished due to wing damage, minimizing roll excursions can be a much harder task. Roll damping can be maintained if the aircraft is flown at a higher speed (lower AOA), so the pilot may have to engage in an appropriate trade-off between retaining a certain level of control versus reducing speed for a safer landing. In addition, because the pilot may be flying well out of trim or symmetric control conditions, the control response may also be highly nonlinear or asymmetric, exacerbating the problem.

It was expected that safely landing under damage would require higher-than-normal touchdown speeds and descent rates, and the intent was to quantify such increases in some fashion as a function of damage level. However, based on combinations of piloting skill and control gain, a range of touchdown conditions from nominal to very high speed was observed. During the landing approach simulations, it was seen that if the damage effect was quickly recognized and actively controlled with high-gain piloting inputs, and the approach was stabilized, then a landing at nominal or near-nominal conditions could be achieved. However, if the approach remained unstabilized for a substantial amount of time, and large excursions from the nominal approach path were allowed by the pilot, landing speeds significantly higher than nominal were sometimes seen (at times 40 to 50 knots higher), as the pilot, in effect, used higher speed/lower AOA to diminish the rolling moment asymmetry and increase the roll damping near touchdown instead of using high-gain inputs.

In the cases studied, the aerodynamic and systems effects of wing damage were for the most part controllable, albeit with higher pilot workload and possibly higher landing speeds. Complete loss of aileron movement on the damaged-wing side was still a controllable condition, although requiring greater pilot workload versus a $50 \%$ reduction in aileron deflection rate. However, when these effects were coupled with loss of engine thrust on the damaged wing, controlling and stabilizing the aircraft was a substantially more difficult task, due to the added, and sometimes conflicting, control inputs needed to compensate for the thrust asymmetry along with the aerodynamic effects. In many cases, controllability was marginal, and the ability to effect a safe landing was considerably diminished. Because these coupled effects (based on very rough modeling of control degradation) resulted in potentially uncontrollable flight or unacceptably high-speed landing conditions, it is important that more extensive and accurate modeling of the thrust and control degradation be conducted for any specific configuration of interest, based on the expected damage. It should also be considered that thrust loss from an engine may result in an inability to maintain level flight, reducing the available time for a flight crew to assess the vehicle's control capability and learn how to fly the "new" aircraft before being required to attempt a landing.

A final aspect that should be considered is the "startle factor." For this study, the pilots were aware of the impending damage effects, and were thus mentally prepared for them, and even so were occasionally unable to land at near-nominal conditions. For aircrews not anticipating such an event, greater time to recognize, react, appropriately understand, and ultimately compensate for the damage would be required, and thus much greater time in an unstabilized approach condition would be expected.

This effort was conducted from an engineering and simulation modeling perspective, utilizing two researchers with general aviation experience acting as pilots; further studies in this area using transport category pilots are planned, and will benefit from their evaluations for is sues related to piloting techniques.

\section{Summary and Concluding Remarks}

A study was undertaken at NASA Langley Research Center to establish, demonstrate, and apply methodology for modeling and implementing the aerodynamic effects of MANPADS damage to a transport aircraft into real-time flight simulation, and to demonstrate a preliminary capability of using such a simulation to conduct an assessment of aircraft survivability. A summary of the main conclusions of this activity is given below. 
1. Incremental static aerodynamic effects were computed from the wind tunnel data and applied to the aerodynamic simulation database of a transport configuration. Superpositioning of the incremental aerodynamics on the baseline simulation proved to be a simple and effective method of incorporating the effects, allowing the baseline simulation to be left unchanged. The dynamic effect (roll damping) could not be applied in this fashion, and was applied instead as a multiplier to the rolling moment increment due to roll rate.

2. The specific change in vehicle mass properties for the damage conditions was not modeled; rather, the effect of a large, asymmetric mass change (physical separation of an engine) was modeled to ascertain if such a change would have a significant effect. A substantial effect was not seen, therefore it was concluded that relative to the aerodynamic and control issues, the effect of mass properties due to wing damage was not significant.

3. Aerodynamic rolling moment asymmetry increases with angle of attack; therefore greater roll control input is required as the aircraft decelerates to maintain wings-level flight. Adequate margin must be maintained to allow enough control for maneuvering during low speed flight; this will result in a minimum landing speed that may be higher than normal. The use of sideslip to compensate for the roll asymmetry can increase the amount of roll control available for maneuvering.

4. The combined effects of aerodynamics and degraded control capability modeled in this study resulted in higher pilot workload and difficulty in controlled maneuvering, but were ultimately manageable. The need to maintain precise airspeed control at low speeds near touchdown and the utility of employing sideslip to compensate for roll asymmetry were found to be significant issues from a controllability standpoint. However, the additional factor of engine thrust loss resulted in significantly reduced controllability, bordering in some cases to almost uncontrollable for a safe landing.

5. MANPADS damage to the wing does not necessarily result in higher touchdown speed and descent rate; however, if the pilot does not "stay on top" of the aircraft with high-gain control inputs, and allows large excursions from the nominal approach path, high landing speeds (as much as 40-50 knots higher) may be required in order to maintain adequate control.

6. Damage to systems resulting in degraded control beyond what was modeled in this activity (aileron effects only) can have much greater influence on continued controllability or maneuverability. For example, hydraulic systems damage may also reduce pitch control authority, resulting in significantly greater pilot workload to compensate for pitch excursions in addition to the lateral effects discussed here.

\section{References}

${ }^{1}$ Shah, Gautam H.; Cunningham, Kevin; Foster, John V.; Fremaux, C. Michael; Stewart, Eric C.; Wilborn, James E; Gato, William; and Pratt, Derek W.: Wind Tunnel Investigation of Commercial Transport Aircraft Aerodynamics at Extreme Flight Conditions. SAE-2002-01-2912, Presented at SAE World Aviation Congress, Phoenix, AZ, November 2002.

${ }^{2}$ Foster, John V., Cunningham, Kevin, Fremaux, Charles M., Shah, Gautam H., Stewart, Eric C., Rivers, Robert A., Wilborn, James E., and Gato, William: Dynamics Modeling and Simulation of Large Transport Airplanes in Upset Conditions, AIAA-2005-5933, Presented at 2005 AIAA Guidance, Navigation, and Control Conference, San Francisco, CA, August 2005.

${ }^{3}$ Cunningham, Kevin, Foster, John V., Shah, Gautam H., Stewart, Eric C., Ventura, Robin N., Rivers, Robert A., Wilborn, James E., and Gato, William: Simulation Study of Flap Effects on a Commercial Transport Airplane in Upset Conditions, AIAA-2005-5908, Presented at 2005 AIAA Atmospheric Flight Mechanics Conference, San Francisco, CA, August 2005.

${ }^{4}$ Shah, Gautam H.: Aerodynamic Effects and Modeling of Damage to Transport Aircraft, AIAA-20086203, Presented at 2008 AIAA Atmospheric Flight Mechanics Conference, Honolulu, HI, August 2008. 